\title{
BMP7 reduces inflammation and oxidative stress in diabetic
}

\author{
tubulopathy \\ Rui Xi Li, Wai Han Yiu, Hao Jia Wu, Dickson W. L. Wong, Loretta Y. Y. Chan, Miao Lin, \\ Joseph C. K. Leung, Kar Neng Lai, Sydney C.W. Tang \\ Division of Nephrology, Department of Medicine, The University of Hong Kong, Queen Mary \\ Hospital, Hong Kong \\ Key words: diabetes mellitus, advanced glycation end products, db/db mice, renal tubular \\ cells \\ Short title: Bone morphogenetic protein 7 attenuates diabetic tubulopathy

\begin{abstract}
Abbreviations: BMP7, Bone Morphogenetic Protein 7; AGEs, advanced glycation end products; HSA, human serum albumin; PTECs, proximal tubular epithelial cells; DN, diabetic nephropathy; T2DN, type 2 diabetic nephropathy; ESRD, end stage renal disease; IL-1 $\beta$, Interleukin-1 beta; TNF- $\alpha$, tumor necrosis factor alpha; TGF- $\beta$, transforming growth factor beta; IL-8, Interleukin 8; IL-6, Interleukin 6; ICAM1, Intercellular Adhesion Molecule 1; MCP1, monocyte chemoattractant protein 1; CTGF, connective tissue growth factor; MAPK, mitogen-activated protein kinase; ERK, extracellular regulated protein kinases; Unx, uninephrectomy; ROS, reactive oxygen species; BUN, blood urea nitrogen; UACR, urine albumin to creatinine ratio; STZ, streptozotocin; REBM, renal epithelial cell basal medium; TBA, thiobarbituric acid; MDA, malondialdehyde; PAS, Periodic Acid-Schiff (PAS); IOD, integrated optical density.
\end{abstract}

\section{Summary Statement}

BMP7 ameliorates diabetic tubulopathy by suppressing inflammatory and oxidative stress responses both in cultured renal tubular cells exposed to advanced glycation end products and in diabetic $d b / d b$ mice.

Word count: 3,871 (excluding title page, abstract, figure legends, tables and references) plus 10 figures and 2 tables

\section{ADDRESS FOR CORRESPONDENCE:}

Sydney C.W. Tang, Division of Nephrology, Department of Medicine, The University of Hong Kong, Queen Mary Hospital, 102 Pokfulam Road, Hong Kong. Phone: (852) 2255 3879; Fax: (852) 2872 5828; Email: scwtang@, hku.hk 


\begin{abstract}
Bone morphogenetic protein 7 (BMP7) has been reported to confer renoprotective effects in acute and chronic kidney disease models, but its potential role in type 2 diabetic nephropathy remains unknown. In cultured human proximal tubular epithelial cells (PTECs), exposure to advanced glycation end products (AGEs) induced overexpression of intercellular adhesion molecule 1 (ICAM1), monocyte chemoattractant protein 1 (MCP1), interleukin 8 (IL-8) and interleukin 6 (IL-6), involving activation of p44/42 and p38 mitogen-activated protein kinase (MAPK) signaling. BMP7 dose-dependently attenuated AGE-induced upregulation of ICAM1, MCP1, IL-8 and IL-6 at both mRNA and protein levels. Moreover, BMP7 suppressed AGE-induced p38 and p44/42 MAPK phosphorylation and reactive oxygen species production in PTECs. Compared with vehicle control, uninephrectomized $d b / d b$ mice treated with BMP7 for 8 weeks had significantly lower urinary albumin-to-creatinine ratio $(3,549 \pm 816.2 \mu \mathrm{g} / \mathrm{mg} v \mathrm{~s}$. $8,612 \pm 2,037 \mu \mathrm{g} / \mathrm{mg}, p=0.036)$, blood urea nitrogen $(33.26 \pm 1.09 \mathrm{mg} / \mathrm{dL} v s .37 .49 \pm 0.89 \mathrm{mg} / \mathrm{dL}$, $p=0.006$ ), and renal cortical expression of ICAM1 and MCP1 at both gene and protein levels. In addition, BMP7-treated animals had significantly less severe tubular damage, interstitial inflammatory cell infiltration, renal cortical p38 and p44/42 phosphorylation, and lipid peroxidation. Our results demonstrated that BMP7 attenuates tubular pro-inflammatory responses in diabetic kidney disease by suppressing oxidative stress and multiple inflammatory signaling pathways including p38 and p44/42 MAPK. Its potential application as a therapeutic molecule in diabetic nephropathy warrants further investigation.
\end{abstract}




\section{INTRODUCTION}

Diabetic nephropathy (DN) is the leading cause of end stage renal disease (ESRD) in most developed countries [1], and over $90 \%$ are due to type 2 diabetes. Although the precise pathogenetic mechanisms of type 2 diabetes have yet to be worked out, emerging evidence strongly suggests an inflammatory component involving activation of the circulating complement system and pro-inflammatory chemokines and cytokines [2], which are closely associated with the development and progression of DN [3]. Despite current recommendations of full RAS blockade and stringent glycemic, lipid, and blood pressure control, the residual risk of renal progression in DN has remained high. Short of a specific protocol, it is conceivable that any therapeutic approach that intervene the downstream tubulotoxic effects of T2DN is a promising alternative for renoprotection. Anti-inflammatory concept open a new door for DN treatment, pre-clinical trials and clinical trials have been launched targeted specific cytokines, such as IL-1 $\beta$ specific antibody $[4,5]$, TNF blocker [6], or modulating pro-inflammatory pathways [7-9]. Although the results of some of these clinical trials are promising, their overall clinical utilities are still limited [2]. Therefore, the development of additional therapeutic interventions remains a major priority.

Bone morphogenetic protein 7 (BMP7) is a homodimeric protein that belongs to the TGF- $\beta$ superfamily. BMP7 is vital for kidney development and is only selectively expressed in several adult organs including kidney [10]. BMP7 has been reported to be down regulated under several disease conditions [11-13], and administration of exogenous BMP7 has been shown to inhibit injury in acute or chronic kidney disease [14-16]. For diabetic nephropathy, BMP7 has been reported to preserve podocytes [17] and rescue type1 DN [18-21]. However, most of these studies mainly focused on the anti-fibrotic role of BMP7. Gould et al. reported that BMP7 suppressed TNF-alpha induced pro-inflammatory cytokines in PTECs [22], and Wang et al. also reported that BMP7 reduced tubulointerstitium macrophage infiltration in STZ-induced DN [21], suggesting an anti-inflammatory role of BMP7.

Tubular damage is a major feature of DN [23-27], and tubulointerstitium lesions are predictive of renal function and prognosis in DN patients [28]. We recently found that different kinds of AGEs caused differential effects on renal tubular cell inflammation [29, 30], however, whether BMP7 can prevent AGE-induced kidney injuries or preserve kidney function in type 2 DN remains unknown. Herein, we explored the potential anti-inflammatory role of BMP7 in AGE-induced tubular injury in vitro and in a murine model of type $2 \mathrm{DN}$.

\section{METHODS AND MATERIALS}

\section{Cell culture}

Primary human renal proximal tubular epithelial cells (PTECs) were purchased from Lonza (Walkersville, MD, USA). Cells were cultured in Renal Epithelial Cell Basal Medium (REBM) with supplemented growth factors and maintained at $37^{\circ} \mathrm{C}$ in $5 \% \mathrm{CO}_{2}$ and $95 \%$ air. In all experiments, cells (from passage $2-4$ ) were grown to $70 \sim 80 \%$ confluency and were arrested in 
serum-free medium for $24 \mathrm{~h}$ before stimulation. Cells were stimulated with advanced glycation end products of human serum albumin (AGEs) $(100 \mu \mathrm{g} / \mathrm{ml}$, Sigma-Aldrich, St. Louis, MO) with or without BMP7 (100 ng/ml, R\&D Systems, Minneapolis, MN). Inhibitors of p38 (SB203580 $10 \mu \mathrm{M}$ ), p44/42 MAPK (PD98059 $25 \mu \mathrm{M}$ ) signalling pathways were added into the culture system, gene and protein level of different cytokines and chemokines were detected. Unless otherwise specified, PTECs were harvested at $3 \mathrm{~h}$ or $24 \mathrm{~h}$ after stimulation for gene and protein expression study respectively.

\section{Animal Model}

For in vivo study, genetically diabetic male $d b / d b$ mice and their non-diabetic $d b / m$ littermates (The Jackson Laboratory, Bar Harbor, ME, USA) were used. All work with mice was approved by the Committee on the Use of Live Animals in Teaching and Research of The University of Hong Kong, and was performed in accordance with the NIH Guide for the Care and Use of Laboratory Animal.

At age of 9 weeks, mice underwent uninephrectomy (Unx) or sham operation as described previously [32]. Briefly, a dorsal-ventral incision was made on the right side of the abdominal cavity in anaesthetized mice, the right renal pedicle was identified and ligated followed by carefully dissected out of the kidney. Then the abdominal wall and skin was sutured. Sham-operated mice were also anaesthetized and had their abdominal cut and right renal pedicle manipulated without ligation. The animals were then warmed in intensive care unit full recovery from anesthesia. Two weeks after operation, Unx and sham-operated mice were randomized into 4 groups ( $\mathrm{n}=10 \sim 11$ each): $d b / d b$ sham group, Unx $d b / d b$ vehicle group, Unx $d b / d b$ BMP7 group and Unx $d b / m$ vehicle group and received BMP7 (300 $\mu \mathrm{g} / \mathrm{kg}$ body weight) or equivalent volume of vehicle intraperitoneally every other day. After 8 weeks of treatment, all mice were sacrificed and the kidney were harvested, half of the kidney was snap frozen in liquid nitrogen and stored at $-70^{\circ} \mathrm{C}$ for mRNA and protein extraction. The other half was fixed with $10 \%$ formalin and embedded in paraffin for histological study. Systolic blood pressure was measured by using a computerized tail cuff system (Visitech Systems, Cary, NC). Twenty-four hour urine samples were collected by metabolic cages. Serum was drawn and separated from the sub-mandibular vein at baseline and end point and stored at $-70^{\circ} \mathrm{C}$ for further investigation.

\section{Total RNA extraction and real-time PCR}

Total RNA was extracted from the cultured cells and kidney cortical tissue using Trizol reagent (Invitrogen, Carlsbad, CA) and was reverse transcribed to cDNA with High Capacity cDNA Reverse Transcription Kits (Applied Biosystems, Foster City, CA, USA). Real-time PCR analysis was performed using SYBR green Master Mix (Applied Biosystems) according to the manufacturer's instruction, the amplification was carried out in an ABI Prism 7500 sequence detection system (Applied Biosystems). The primer sequences used in both in vitro and in vivo studies were listed as Table 2. The relative quantification of cDNA in each sample was 
normalized to $\beta$-actin cDNA and the data was analyzed by the SDS software (Applied Biosystems). Data were presented as relative fold change compared to the control.

\section{ELISA}

Pro-inflammatory cytokine expressions were measured in $24 \mathrm{~h}$ condition medium. ICAM1, MCP1, IL-8 and IL-6 protein levels were quantified using commercial kit (PeproTech, Rocky Hill, NJ) following the manufacturer's instructions. Renal cortical protein was extracted by using RIPA lysis buffer (Millipore, Bedford, USA), cortical MCP1 and ICAM1 levels were detected with mouse MCP1 and ICAM1 Duoset ELISA kit (R\&D Systems,) respectively.

\section{Western blot analysis}

Growth-arrested PTECs were stimulated with AGEs $(100 \mu \mathrm{g} / \mathrm{mL})$ with or without BMP7 (100 $\mathrm{ng} / \mathrm{mL}$ ) for $30 \mathrm{~min}$. Cells were washed with PBS and then lysed with lysis buffer containing protease inhibitor (Sigma Aldrich) as previously described [33]. Total protein concentrations were determined by Pierce BCA method (Thermo Scientific, Rockford, USA). Equal amount of proteins were dissolved in loading buffer and denatured by boiling at $95^{\circ} \mathrm{C}$ for $10 \mathrm{~min}$. Protein samples were run on $12 \%$ SDS-PAGE gel and transferred to PVDF membrane (Millipore). Membrane were blocked with 5\% non-fat milk and incubated overnight with primary antibodies against phosphor-p38 MAPK (1:1000), p38 MAPK (1:2000), phosphor-p44/42 (1:2000) and p44/42 (1:2000) (Cell Signaling Technology, Beverly, MA) in Tris-buffered saline with $0.1 \%$ Tween-20, and subsequently incubated with horseradish peroxidase-conjugated secondary antibodies (Dako, Carpinteria, CA) for $2 \mathrm{~h}$. Reactions were visualized by using ECL plus chemiluminescence (GE Healthcare, Buckinghamshire, UK) with ChemiDoc XRS+ system (Bio-Rad, Hercules, CA). Density of bands were quantified by bundled ChemiDoc software and normalized by actin level.

\section{Detection of intracellular reactive oxygen species}

Intracellular reactive oxygen species (ROS) were measured using OxiSelect ${ }^{\mathrm{TM}}$ Intracellular ROS Assay Kit (Cellbiolabs, San Diego, CA) according to the manufacturer's instruction. Briefly, PTECs were pretreated with DCFH-DA (dissolved in DMEM) for $1 \mathrm{~h}$, cells were washed and stimulated with plain medium or medium with AGEs, AGEs with BMP7 and $\mathrm{H}_{2} \mathrm{O}_{2}$ for $1 \mathrm{~h}$, then were lysed for fluorescence measurement using FLUOStar Omega plate reader (BMG labtech, Germany) for excitation at $485 \mathrm{~nm}$ and emission at $520 \mathrm{~nm}$.

PTECs were seeded in 8-well chamber slides (Nunc Lab-Tek II, Thermo Scientific, USA) and growth-arrested for $24 \mathrm{~h}$ until $80 \%$ confluence. Cells then treated with AGEs, AGEs with BMP7, $\mathrm{H}_{2} \mathrm{O}_{2}(500 \mu \mathrm{M})$ as positive control and plain medium as normal control. After $1 \mathrm{~h}$ incubation, cells were washed with PBS and incubated with an oxidative stress indicator CM- $\mathrm{H}_{2}$ DCFDA (500 $\mu \mathrm{M}$, Invitrogen) for $45 \mathrm{~min}$, then cells were washed with PBS and fixed with 4\% paraformaldehyde for $15 \mathrm{~min}$. Slides were mounted with Vectashield and 
4',6-diamidino-2-phenylindole (DAPI) (Vector Laboratories, Burlingame, USA) and visualized under fluorescence microscope.

\section{Quantitation of MDA level in renal tissue}

Lipid peroxidation of renal cortical tissue was determined by using OxiSelect ${ }^{\text {TM }}$ TBARS Assay Kit (Cell Biolabs) according to the manufacturer's instruction. Tissue lysate or MDA standard was incubated with SDS lysis solution for $5 \mathrm{~min}$ at room temperature; Thiobarbituric acid (TBA) was added to the mixture and incubated at $95^{\circ} \mathrm{C}$ for $60 \mathrm{~min}$. Supernatant of the lysate was then transferred into 96-well plate and read for absorbance at $540 \mathrm{nM}$. Data was presented as fold change of MDA-TBA adduct compared with the $d b / d b$ sham group.

\section{Biochemical analysis of serum and urine specimens}

Urine albumin concentration was determined by mouse albumin ELISA kit (Bethyl Laboratories, Montgomery, TX), Urine creatinine, serum blood urea nitrogen (BUN) and blood glucose concentrations were measured by enzymatic method using commercially available test kits (Stanbio Laboratory, Boerne, TX).

\section{Histological examination and immunohistochemistry}

Periodic Acid-Schiff (PAS) staining (Sigma-Aldrich) was performed in $4 \mu \mathrm{m}$ paraffin sections following the manufacturer's protocol. Glomerular and tubulointerstitial damage of kidney were quantified by Image Pro Plus Software 5.0 (Media Cybernetics, Silver Spring, USA), thirty fields in the cortex were randomly selected to collect the integrated optical density of lesions and area of the field. Data were presented as the average integrated optical density per area (IOD/Area) value.

Immunohistochemistry was performed to detect macrophage cell marker F4/80. Four micrometers paraffin sections were deparaffinized and rehydrated through a descending ethanol gradient. Enzymatic digestion with protease protease $\mathrm{K}$ was used for antigen retrieval.

Sections were incubated with anti-F4/80 antibody (1:50, Serotec, Oxford, UK) at $4{ }^{\circ} \mathrm{C}$ overnight and subsequently HRP-conjugated secondary antibodies. Positive staining was visualized as brown color using DAB substrate (Dako). The number of $\mathrm{F} 4 / 80^{+}$cells was counted in 20 randomly selected high-power cortical fields per kidney section and expressed as the average number of cells per field (number/HPF).

\section{Statistical analysis}

All data were presented as means \pm standard error unless otherwise specified. Statistical analysis was performed using GraphPad Prism 5.0 for Windows (GraphPad Software Inc., San Diego, USA). Difference between multiple groups was analyzed by one-way ANOVA with Bonferroni's intergroup comparison. $p<0.05$ was considered statistically significant. 


\section{RESULTS}

\section{BMP7 attenuated AGE-induced pro-inflammatory response in PTECs}

Real-time PCR showed that AGEs $(100 \mu \mathrm{g} / \mathrm{mL})$ superinduced expression of ICAM1 and IL-8 over equivalent doses of HSA in PTECs, and BMP7 dose-dependently attenuated this response. The optimal dosage of BMP7 at $100 \mathrm{ng} / \mathrm{mL}$ was used in this study (Figure 1).

The anti-inflammatory effect of BMP7 was confirmed by the expression profile of other cytokines. Real-time PCR and ELISA results revealed that BMP7 reduced AGE-induced overexpression of monocyte chemoattractant protein-1 (MCP1), Interleukin 8 (IL-8), Intercellular Adhesion Molecule 1 (ICAM1), and Interleukin 6 (IL-6) in PTECs in both gene and protein levels. (Figure 2)

\section{AGEs induced pro-inflammatory responses through multiple signaling pathways in PTECs}

Pretreatment of PTECs with MAPK inhibitors attenuated AGE-induced cytokine expressions. Inhibition of p38 signalling with SB203580 reduced overexpression of IL-8 and MCP1, and inhibition of p44/42 signalling with PD98059 reduced upregulation of IL-8 and ICAM1 (Figure 3). Suggested AGEs induced pro-inflammatory responses through multiple signaling pathways.

\section{BMP7 suppressed AGE-induced phosphorylation of p38 and $44 / 42$ protein}

To test whether anti-inflammatory effect of BMP7 is mediated through MAPK pathways, phosphorylation of p38 and p44/42 protein was determined by western blot analysis. Figure 4 showed that AGEs increased p38 and p44/42 phosphorylation in PTECs, whereas co-incubation with BMP7 suppressed their phosphorylation significantly. This result suggests that BMP7 attenuates AGE-induced pro-inflammatory responses through modulating p38 and p44/42 MAPK signalling pathway.

\section{BMP7 attenuated AGE-induced reactive oxygen species (ROS) accumulation in PTECs}

Considering that AGEs may induce cellular oxidative stress, also, increased ROS production may lead to the activation of p44/42 or p38 MAPK [34], ROS formation was measured in AGE-stimulated PTECs. Immunofluorescence study showed that after stimulation with AGEs for $1 \mathrm{~h}$, ROS accumulation was significantly higher than the medium control, AGEs co-incubated with BMP7 reduced ROS formation in PTECs. Quantitative intracellular ROS measurement by OxiSelect ${ }^{\mathrm{TM}}$ Intracellular ROS Assay Kit also showed a 50\% increase in ROS formation in AGE-stimulated cells and it was abolished by co-incubated with BMP7 (Figure 5).

\section{BMP7 preserved kidney function and kidney morphology in diabetic kidney}

At the age of 9 weeks, diabetic $d b / d b$ mice have already developed hyperglycemia (blood glucose) obesity (body weight), manifestation of albuminuria (UACR) and reduction of kidney function (BUN) compared with non-diabetic $d b / m$ mice as shown in Table 1 . BMP7 did not affected blood glucose level and systolic blood pressure throughout the experiment. Unx $\mathrm{db} / \mathrm{m}$ 
mice showed a slightly increase in systolic blood pressure and serum BUN $(p<0.05)$ after 8 weeks of treatment, however Unx did not show any effect on these parameters on $d b / d b$ mice. As reported in our previous study [32], Unx markedly exaggerated UACR and serum BUN level in $d b / d b$ mice compared with sham-operated $d b / d b$ mice in this study. Average UACR of Unx- $d b / d b$ vehicle group was 2 fold higher than Unx $d b / d b$ mice received BMP7 injection (8612 $\pm 2037 \mu \mathrm{g} / \mathrm{mg}$ vs. $3549 \pm 816.2 \mu \mathrm{g} / \mathrm{mg}, p=0.036)$. Serum BUN of Unx- $d b / d b$ mice treated with BMP7 showed significantly lower level $(33.26 \pm 1.09 \mathrm{mg} / \mathrm{dL}$ vs. $37.49 \pm 0.89 \mathrm{mg} / \mathrm{dL}$, $p=0.006$ ) when compared with Unx- $d b / d b$ vehicle group.

Morphologically, sham-operated $d b / d b$ mice displayed mild glomerular and tubulointerstitial damage, while Unx- $d b / d b$ mice developed glomerular hypertrophy, nodular glomerulosclerosis and severe tubular damage (tubular dilation and atrophy), and such glomerular and tubular damages were partially abrogated by BMP7 treatment (Figure 6).

\section{BMP7 attenuated renal cortical inflammation and macrophage infiltration in diabetic mice}

To explore whether exogenously administration of BMP7 confers similar anti-inflammatory effect in diabetic kidney as shown in the in vitro study, cortical expression of pro-inflammatory cytokines ICAM1 and MCP1 were examined by real-time PCR and ELISA. Diabetes caused overexpression of MCP1 and ICAM1 in Unx- $d b / d b$ mice in both gene and protein levels when compared to Unx- $d b / m$ control mice (Figure 7). A significant increase in macrophage infiltration in the tubulointerstitium was also observed in parallel with the upregulation of MCP1 and ICAM1 in Unx diabetic kidney (Figure 8). Administration of BMP7 reduced renal cortical expression of MCP1 and ICAM1 at $40 \%$ and $16.7 \%$ respectively when compared to Unx- $d b / d b$ vehicle group.

\section{BMP7 suppressed p38 and p44/42 MAPK activation in DN}

To explore the possible molecular mechanisms of BMP7 in modulating diabetic kidney inflammation, Western blot analysis demonstrated a significantly increase in cortical p38 and p44/42 MAPK phosphorylation in Unx- $d b / d b$ mice injected with vehicle than mice received sham-operation. Treatment of BMP7 significantly suppressed $40 \%$ of $\mathrm{p} 38$ and $60 \%$ of $\mathrm{p} 44 / 42$ MAPK phosphorylation, suggesting that BMP7 exerts in vivo anti-inflammatory effect by modulating these MAPK pathways in diabetic kidney (Figure 9).

\section{BMP7 reduced cortical lipid peroxidation in diabetic kidney}

The degree of oxidative stress in renal cortex was determined by measuring the end product of lipid peroxidation. Aldehydic secondary products malondialdehyde (MDA) in the kidney reacted with thiobarbituric acid (TBA) to form the MDA-TBA adduct, which can be measured colorimetrically. Lipid peroxidation was significantly higher in Unx- $d b / d b$ vehicle group than the other groups ( $d b / d b$ sham, Unx- $d b / d b$ BMP7 and Unx- $d b / m$ groups, $p<0.01$.). Administration of BMP7 reduced 20\% of MDA formation in diabetic kidney (Figure 10). 


\section{DISCUSSION}

BMP7 has been demonstrated to have profound anti-fibrotic effects in the diabetic kidney, as demonstrated mainly in STZ-induced animal models, reflecting type 1 diabetes. Herein, we showed for the first time that BMP7 also possesses anti-inflammatory effects in renal tubular epithelial cells and in a model of type 2 diabetic nephropathy.

In vitro, BMP7 attenuated AGE-induced tubular inflammation through suppressing multiple pathways including p38 and p44/42 MAPK. A strength of these in vitro data stems from the fact that they were derived using primary human proximal tubular epithelial cells that offer a good viable model for the proximal tubule epithelia. Although immortalized human-transformed cell lines have been extensively used and are extremely useful for these purposes, they exhibit limitations in their phenotypic resemblance to primary PTECs in culture [31]. In vivo, we demonstrated that BMP7 restored renal function and abrogated cortical inflammation in T2DN. Finally, BMP7 exerted anti-oxidative effects both in vitro and in vivo.

Our findings are in line with previous observations in certain non-diabetes-related investigations. For instance, BMP7 repressed TNF- $\alpha$ induced pro-inflammatory chemokines and cytokines in primary human PTECs [22]. Lee et al. found that BMP7 significantly inhibited constitutive and IL1- $\beta$ induced MCP1 expression in mesangial cells by modulating the JNK/AP1 pathway [35]. Administration of BMP7 decreased IL-1 $\beta$ production in an inflammatory arthritis rat model [36]. Our previous study also demonstrated that BMP7 suppressed polymeric IgA induced TNF- $\alpha$ overexpression [37]. In diabetes, BMP7 reduced monocyte/macrophage infiltration in a STZ-induced diabetic rat model [21]. All these data suggested BMP7 conferred anti-inflammatory effect both in vitro and in vivo. It is likely that AGEs induce pro-inflammatory chemokine and cytokine overexpression by activating multiple intracellular signaling pathways, as the inhibition of a single signal transduction pathway could only suppress the expression of certain pro-inflammatory factors or even induced the expression of other factors (data not shown). Our in vivo results using $d b / d b$ animals also revealed inhibition of p38 and p44/42 signaling pathways and their downstream genes by exogenous BMP7. So we believe BMP7 reduced various pro-inflammatory factors in AGE-induced tubular inflammation, mostly because BMP7 simultaneously suppressed multiple signaling pathways including the $\mathrm{p} 38$ and p44/42 MAPK.

In addition to its action on the renal tubules, BMP7 may also exert notable glomerular effects in the context of diabetic nephropathy. In vitro, BMP7 ameliorated glucose-induced oxidative stress via inhibition of PKC, JNK phosphorylation and c-jun activation in rat mesangial cells [38], and reduced apoptosis by blocking HG-mediated caspase-3 overactivity in podocytes [17]. In addition, treatment with BMP7 restored synaptopodin and podocin expression in mouse podocytes exposed to HG [39]. In vivo, transgenic expression of human BMP7 in STZ-induced diabetic mice reduced glomerulosclerosis, interstitial collagen, albuminuria, podocyte dropout and increased nephrin levels compared with wild type animals [18]. In STZ-induced diabetic CD1 mice with renal lesions resembling human DN, BMP7 inhibited glomerular hypertrophy and glomerulosclerosis, though it was most effective in 
ameliorating tubular inflammation and tubulointerstitial fibrosis [19]. Also in STZ-induced diabetic $\mathrm{C} 57 \mathrm{Bl} / 6 \mathrm{~J} \mathrm{CTGF}^{+/}$mice, there was increased phosphorylation of the BMP signal transduction proteins Smad1/5 and expression of the BMP target gene leading to reduced glomerular basement membrane thickening and albuminuria compared with $\mathrm{CTGF}^{+/+}$mice, suggesting a pathogenetic role of CTGF in BMP signaling in DN [20]. Finally, BMP7 partially restored renal function, reduced albuminuria, and improved glomerular histology toward normal in STZ-induced diabetic rats [21].

Advanced glycation and oxidative stress are 2 key players in the pathogenesis of diabetic nephropathy [40]. Oxidative stress is induced by multiple pathways in diabetes. Hyperglycemia causes excessive ROS synthesis by direct autoxidation during the formation of AGEs and by inducing mitochondrial dysfunction [41]. Experimental studies showed that AGEs can further increase ROS generation through AGE receptor (RAGE) by stimulating NAD(P)H oxidase activity [42] and that AGE-induced oxidative stress is attenuated by NADPH oxidase inhibitor in human endothelial cells [43]. Oxidative stress in diabetes may also be enhanced by a change in antioxidant defence. There is evidence suggesting that AGEs decrease the enzyme activities of SOD and catalase [44] and altered activities of these enzymes are also observed in diabetic animal models. Hence, persistent hyperglycemia and oxidative stress enhance AGEs formation, thus setting up a vicious cycle of auto-amplification culminating in cell injury. Indeed, BMP7 has been shown to attenuate ROS generation in high glucose stimulated rat mesangial cells [38] as stated above. Here, we showed for the first time that BMP7 not only attenuated oxidative stress in HG-exposed mesangial cells, but also reduced ROS formation in AGE-stimulated PTECs, in addition to its anti-inflammatory action. Moreover, BMP7 reduced lipid peroxidation in the diabetic kidney, substantiating the anti-oxidative effects of BMP7 in vivo. Mechanistically, we found BMP7 attenuated ROS formation and suppressed p38 and p44/42 phosphorylation. This is not surprising considering that ROS induced activation of ERK and p38 MAPK [34]. Whether BMP7 modulates the expression of pro-inflammatory cytokines directly or indirectly through ROS generation requires further investigation.

Although a large body of evidence points to an anti-fibrotic role of BMP7 [14, 45-47], mostly stating that BMP7 counteracts the profibrotic effects of TGF- $\beta$ in several disease models [46], there exists opposite views. For instance, Dudas et al. reported that BMP7 failed to attenuate TGF- $\beta$ induced epithelial-to-mesenchymal transition in human PTECs [48], in which cells cultured with BMP7 alone displayed increased vimentin, CTGF or even TGF- $\beta$ expression. Interestingly, we also found that PTECs stimulated with BMP7 had significantly increased CTGF, type I collagen and reduced E-cadherin gene expression. As our mouse model did not develop notable renal fibrosis, we did not observe significant differences of pro-fibrotic markers in different diabetic groups. In addition, Masson Trichrome staining or immunohistochemical staining of collagen I \& V did not yield significant differences among the various diabetic groups (data not shown). Hence, although BMP7 may promote fibrosis in a single cell type in a culture system, it is possible that its overall effects in vivo are the results of interactions between different resident and infiltrating cells, which is beyond the scope of this 
study. Nevertheless, the anti-fibrotic role of BMP7 in T2DN warrants further investigation.

\section{CLINICAL PERSPECTIVES}

ESRD from type $2 \mathrm{DN}$ imposes a heavy burden on most healthcare systems in the developed world, but therapeutic approaches to delay or prevent its occurrence are very limited. Diabetic tubulopathy has recently been shown to play a significant role in intrarenal inflammation during DN. BMP7 ameliorates diabetic tubulopathy by suppressing inflammatory and oxidative stress responses both in cultured renal tubular cells exposed to advanced glycation end products and in diabetic $d b / d b$ mice. It therefore has the potential of being developed into an anti-inflammatory and anti-oxidative agent for the treatment of type 2 diabetic kidney disease.

\section{AUTHOR CONTRIBUTION}

RuiXi Li, Wai Han Yiu and Sydney C.W. Tang designed and performed the experiments, acquired and analysed the data, and drafted the paper. Hao Jia Wu, Dickson W. L. Wong, Loretta Y. Y. Chan, Miao Lin and Joseph C. K. Leung were involved in experiments, data collection and paper preparation. Kar Neng Lai and Sydney C.W. Tang conceived the study, and participated in its design and co-ordination, were involved in drafting the paper and revising it critically for important intellectual content and gave final approval of the version to be published. All authors have read and approved the final version of the paper.

\section{FUNDING}

This study is supported by a General Research Fund of the Research Grants Council [Grant number: HKU7770/09M] of Hong Kong, the National Basic Research Program of China 973 program no. 2012CB517600 [no. 2012CB517606], an Endowment Fund established for the "Yu Professorship in Nephrology" awarded to S.C.W.T., and the Hong Kong Society of Nephrology Research Grant 2012.

\section{ACKNOWLEDGMENTS}

W.H.Y. and H.J.W. are partially supported by Mr. Winston Leung and the Hong Kong Concrete and the Continental Cement and Gypsum Co. Ltd. Part of the results from this study was presented in abstract form at the American Society of Nephrology Renal Week, Nov 7-10, 2013, Atlanta, GA, USA. We sincerely appreciate the time and effort from all who contributed to the present study. 


\section{REFERENCES}

1. Zimmet, P., Alberti, K.G., Shaw, J. Global and societal implications of the diabetes epidemic. Nature 2001; 414: 782-787.

2. Donath, M.Y., Shoelson, S.E. Type 2 diabetes as an inflammatory disease. Nat. Rev. Immunol. 2011; 11: 98-107.

3. Navarro-Gonzalez, J.F., Mora-Fernandez, C. The role of inflammatory cytokines in diabetic nephropathy. J. Am. Soc. Nephrol. 2008; 19: 433-442.

4. Maedler, K., Sergeev, P., Ris, F., Oberholzer, J., Joller-Jemelka, H.I., Spinas, G.A., Kaiser, N., Halban, P.A., Donath, M.Y. Glucose-induced beta cell production of IL-1beta contributes to glucotoxicity in human pancreatic islets. J. Clin. Invest. 2002; 110: 851-860.

5. Yuan, M., Konstantopoulos, N., Lee, J., Hansen, L., Li, Z.W., Karin, M., Shoelson, S.E. Reversal of obesity- and diet-induced insulin resistance with salicylates or targeted disruption of Ikkbeta. Science 2001; 293: 1673-1677.

6. Kiortsis, D.N., Mavridis, A.K., Vasakos, S., Nikas, S.N., Drosos, A.A. Effects of infliximab treatment on insulin resistance in patients with rheumatoid arthritis and ankylosing spondylitis. Ann. Rheum. Dis. 2005; 64: 765-766.

7. Cai, D., Yuan, M., Frantz, D.F., Melendez, P.A., Hansen, L., Lee, J., Shoelson, S.E. Local and systemic insulin resistance resulting from hepatic activation of IKK-beta and NF-kappaB. Nat. Med. 2005; 11: 183-190.

8. de Zeeuw, D., Akizawa, T., Audhya, P., Bakris, G.L., Chin, M., Christ-Schmidt, H., Goldsberry, A., Houser, M., Krauth, M., Lambers Heerspink, H.J., McMurray, J.J., Meyer, C.J., Parving, H.H., Remuzzi, G., Toto, R.D., Vaziri, N.D., Wanner, C., Wittes, J., Wrolstad, D., Chertow, G.M., Investigators, B.T. Bardoxolone methyl in type 2 diabetes and stage 4 chronic kidney disease. N. Engl. J. Med. 2013; 369: 2492-2503.

9. de Zeeuw, D., Coll, B., Andress, D., Brennan, J.J., Tang, H., Houser, M., Correa-Rotter, R., Kohan, D., Lambers Heerspink, H.J., Makino, H., Perkovic, V., Pritchett, Y., Remuzzi, G., Tobe, S.W., Toto, R., Viberti, G., Parving, H.H. The Endothelin Antagonist Atrasentan Lowers Residual Albuminuria in Patients with Type 2 Diabetic Nephropathy. J. Am. Soc. Nephrol. 2014.

10. Helder, M.N., Ozkaynak, E., Sampath, K.T., Luyten, F.P., Latin, V., Oppermann, H., Vukicevic, S. Expression pattern of osteogenic protein-1 (bone morphogenetic protein-7) in human and mouse development. J. Histochem. Cytochem. 1995; 43: 1035-1044.

11. Simon, M., Maresh, J.G., Harris, S.E., Hernandez, J.D., Arar, M., Olson, M.S., Abboud, H.E. Expression of bone morphogenetic protein-7 mRNA in normal and ischemic adult rat kidney. Am. J. Physiol. 1999; 276: F382-389.

12. Wang, S.N., Lapage, J., Hirschberg, R. Loss of tubular bone morphogenetic protein-7 in diabetic nephropathy. J. Am. Soc. Nephrol. 2001; 12: 2392-2399.

13. Bramlage, C.P., Tampe, B., Koziolek, M., Maatouk, I., Bevanda, J., Bramlage, P., Ahrens, K., Lange, K., Schmid, H., Cohen, C.D., Kretzler, M., Muller, G.A. Bone morphogenetic protein (BMP)-7 expression is decreased in human hypertensive nephrosclerosis. BMC Nephrol. 2010; 11: 31 . 
14. Zeisberg, M., Bottiglio, C., Kumar, N., Maeshima, Y., Strutz, F., Muller, G.A., Kalluri, R. Bone morphogenic protein-7 inhibits progression of chronic renal fibrosis associated with two genetic mouse models. Am. J. Physiol. Renal Physiol. 2003; 285: F1060-1067.

15. Yanagita, M., Okuda, T., Endo, S., Tanaka, M., Takahashi, K., Sugiyama, F., Kunita, S., Takahashi, S., Fukatsu, A., Yanagisawa, M., Kita, T., Sakurai, T. Uterine sensitization-associated gene-1 (USAG-1), a novel BMP antagonist expressed in the kidney, accelerates tubular injury. J. Clin. Invest. 2006; 116: 70-79.

16. Dube, P.H., Almanzar, M.M., Frazier, K.S., Jones, W.K., Charette, M.F., Paredes, A. Osteogenic Protein-1: gene expression and treatment in rat remnant kidney model. Toxicol. Pathol. 2004; 32: 384-392.

17. Mitu, G.M., Wang, S., Hirschberg, R. BMP7 is a podocyte survival factor and rescues podocytes from diabetic injury. Am. J. Physiol. Renal Physiol. 2007; 293: F1641-1648.

18. Wang, S., de Caestecker, M., Kopp, J., Mitu, G., Lapage, J., Hirschberg, R. Renal bone morphogenetic protein-7 protects against diabetic nephropathy. J. Am. Soc. Nephrol. 2006; 17: 2504-2512.

19. Sugimoto, H., Grahovac, G., Zeisberg, M., Kalluri, R. Renal fibrosis and glomerulosclerosis in a new mouse model of diabetic nephropathy and its regression by bone morphogenic protein-7 and advanced glycation end product inhibitors. Diabetes 2007; 56: 1825-1833.

20. Nguyen, T.Q., Roestenberg, P., van Nieuwenhoven, F.A., Bovenschen, N., Li, Z., Xu, L., Oliver, N., Aten, J., Joles, J.A., Vial, C., Brandan, E., Lyons, K.M., Goldschmeding, R. CTGF inhibits BMP-7 signaling in diabetic nephropathy. J. Am. Soc. Nephrol. 2008; 19: 2098-2107.

21. Wang, S., Chen, Q., Simon, T.C., Strebeck, F., Chaudhary, L., Morrissey, J., Liapis, H., Klahr, S., Hruska, K.A. Bone morphogenic protein-7 (BMP-7), a novel therapy for diabetic nephropathy. Kidney Int. 2003; 63: 2037-2049.

22. Gould, S.E., Day, M., Jones, S.S., Dorai, H. BMP-7 regulates chemokine, cytokine, and hemodynamic gene expression in proximal tubule cells. Kidney Int. 2002; 61: 51-60.

23. Caramori, M.L., Mauer, M. Diabetes and nephropathy. Curr. Opin. Nephrol. Hypertens. 2003; $12:$ 273-282.

24. Gilbert, R.E., Cooper, M.E. The tubulointerstitium in progressive diabetic kidney disease: more than an aftermath of glomerular injury? Kidney Int. 1999; 56: 1627-1637.

25. Lin, M., Yiu, W.H., Wu, H.J., Chan, L.Y., Leung, J.C., Au, W.S., Chan, K.W., Lai, K.N., Tang, S.C. Toll-like receptor 4 promotes tubular inflammation in diabetic nephropathy. J. Am. Soc. Nephrol. 2012; 23: 86-102.

26. Tang, S.C., Lai, K.N. The pathogenic role of the renal proximal tubular cell in diabetic nephropathy. Nephrol. Dial. Transplant. 2012; 27: 3049-3056.

27. Tang, S.C., Leung, J.C., Lai, K.N. Diabetic tubulopathy: an emerging entity. Contrib. Nephrol. 2011; 170: 124-134.

28. Taft, J.L., Nolan, C.J., Yeung, S.P., Hewitson, T.D., Martin, F.I. Clinical and histological correlations of decline in renal function in diabetic patients with proteinuria. Diabetes 1994; 43: 1046-1051. 
29. Tang, S.C., Chan, L.Y., Leung, J.C., Cheng, A.S., Lin, M., Lan, H.Y., Lai, K.N. Differential effects of advanced glycation end-products on renal tubular cell inflammation. Nephrology (Carlton) 2011; 16: 417-425.

30. Tang, S.C., Leung, J.C., Chan, L.Y., Tsang, A.W., Lai, K.N. Activation of tubular epithelial cells in diabetic nephropathy and the role of the peroxisome proliferator-activated receptor-gamma agonist. J. Am. Soc. Nephrol. 2006; 17: 1633-1643.

31. Sharpe, C.C., Dockrell, M.E. Primary culture of human renal proximal tubule epithelial cells and interstitial fibroblasts. Methods Mol. Biol. 2012; 806: 175-185.

32. Tang, S.C., Chan, L.Y., Leung, J.C., Cheng, A.S., Lan, H.Y., Lai, K.N. Additive renoprotective effects of B2-kinin receptor blocker and PPAR-gamma agonist in uninephrectomized $\mathrm{db} / \mathrm{db}$ mice. Lab. Invest. 2011; 91: 1351-1362.

33. Tang, S.C., Chan, L.Y., Leung, J.C., Cheng, A.S., Chan, K.W., Lan, H.Y., Lai, K.N. Bradykinin and high glucose promote renal tubular inflammation. Nephrol. Dial. Transplant. 2010; 25: 698-710.

34. Son, Y., Cheong, Y.K., Kim, N.H., Chung, H.T., Kang, D.G., Pae, H.O. Mitogen-Activated Protein Kinases and Reactive Oxygen Species: How Can ROS Activate MAPK Pathways? J Signal Transduct 2011; 2011: 792639.

35. Lee, M.J., Yang, C.W., Jin, D.C., Chang, Y.S., Bang, B.K., Kim, Y.S. Bone morphogenetic protein-7 inhibits constitutive and interleukin-1 beta-induced monocyte chemoattractant protein-1 expression in human mesangial cells: role for JNK/AP-1 pathway. J. Immunol. 2003; 170: 2557-2563.

36. Takahashi, T., Muneta, T., Tsuji, K., Sekiya, I. BMP-7 inhibits cartilage degeneration through suppression of inflammation in rat zymosan-induced arthritis. Cell Tissue Res. 2011; 344: 321-332.

37. Chan, W.L., Leung, J.C., Chan, L.Y., Tam, K.Y., Tang, S.C., Lai, K.N. BMP-7 protects mesangial cells from injury by polymeric IgA. Kidney Int. 2008; 74: 1026-1039.

38. Yeh, C.H., Chang, C.K., Cheng, M.F., Lin, H.J., Cheng, J.T. The antioxidative effect of bone morphogenetic protein-7 against high glucose-induced oxidative stress in mesangial cells. Biochem. Biophys. Res. Commun. 2009; 382: 292-297.

39. De Petris, L., Hruska, K.A., Chiechio, S., Liapis, H. Bone morphogenetic protein-7 delays podocyte injury due to high glucose. Nephrol. Dial. Transplant. 2007; 22: 3442-3450.

40. Tan, A.L., Forbes, J.M., Cooper, M.E. AGE, RAGE, and ROS in diabetic nephropathy. Semin. Nephrol. 2007; 27: 130-143.

41. Ward, M.S., Fortheringham, A.K., Cooper, M.E., Forbes, J.M. Targeting advanced glycation endproducts and mitochondrial dysfunction in cardiovascular disease. Curr. Opin. Pharmacol. 2013; 13: 654-661.

42. Serpillon, S., Floyd, B.C., Gupte, R.S., George, S., Kozicky, M., Neito, V., Recchia, F., Stanley, W., Wolin, M.S., Gupte, S.A. Superoxide production by NAD(P)H oxidase and mitochondria is increased in genetically obese and hyperglycemic rat heart and aorta before the development of cardiac dysfunction. The role of glucose-6-phosphate dehydrogenase-derived NADPH. Am. J. 
Physiol. Heart Circ. Physiol. 2009; 297: H153-162.

43. Wautier, M.P., Chappey, O., Corda, S., Stern, D.M., Schmidt, A.M., Wautier, J.L. Activation of NADPH oxidase by AGE links oxidant stress to altered gene expression via RAGE. Am. J. Physiol. Endocrinol. Metab. 2001; 280: E685-694.

44. Jiang, J.M., Wang, Z., Li, D.D. Effects of AGEs on oxidation stress and antioxidation abilities in cultured astrocytes. Biomed. Environ. Sci. 2004; 17: 79-86.

45. Wang, S., Hirschberg, R. BMP7 antagonizes TGF-beta -dependent fibrogenesis in mesangial cells. Am. J. Physiol. Renal Physiol. 2003; 284: F1006-1013.

46. Boon, M.R., van der Horst, G., van der Pluijm, G., Tamsma, J.T., Smit, J.W., Rensen, P.C. Bone morphogenetic protein 7: a broad-spectrum growth factor with multiple target therapeutic potency. Cytokine Growth Factor Rev. 2011; 22: 221-229.

47. Nguyen, T.Q., Goldschmeding, R. Bone morphogenetic protein-7 and connective tissue growth factor: novel targets for treatment of renal fibrosis? Pharm. Res. 2008; 25: 2416-2426.

48. Dudas, P.L., Argentieri, R.L., Farrell, F.X. BMP-7 fails to attenuate TGF-beta1-induced epithelial-to-mesenchymal transition in human proximal tubule epithelial cells. Nephrol. Dial. Transplant. 2009; 24: 1406-1416. 


\section{FIGURE LEGENDS}

Figure 1. BMP7 dose-dependently reduced AGE-induced tubular inflammation. A. PTECs stimulated with AGE $(100 \mu \mathrm{g} / \mathrm{mL})$ and co-incubated with increasing concentrations of BMP7 (0-200 ng/mL) for $3 \mathrm{~h}$; B. PTECs were stimulated with same concentration $(100 \mu \mathrm{g} / \mathrm{mL})$ of AGE and HSA, co-incubated with or without BMP7 for $3 \mathrm{~h}$. mRNA expression was determined by real-time PCR. $* p<0.05, * * p<0.01, * * * p<0.001$.

Figure 2. BMP7 attenuated AGE-induced pro-inflammatory response in PTECs. A. mRNA expression of MCP1, IL-8, ICAM1 and IL-6 in PTECs cultured with AGEs (100 $\mu \mathrm{g} / \mathrm{mL})$, AGEs plus BMP7 (100 ng/mL) or BMP7 alone. Nil denotes medium control. mRNA were collected after $3 \mathrm{~h}$ of treatment. B. Secreted MCP1, ICAM1, IL-6 and IL-8 levels in culture supernatants, collected at $24 \mathrm{~h}$ and measured by ELISA respectively.

Figure 3. AGE-induced PTECs expression of pro-inflammatory factors is mediated through multiple pathways. PTECs were pre-treated with $\mathrm{p} 44 / 42$ inhibitor (PD98059, $25 \mu \mathrm{M}$ ) or p38 inhibitor (SB203580, $10 \mu \mathrm{M}$ ) 30min before adding AGEs into the culture medium. 3h mRNA and $24 \mathrm{~h}$ supernatants were collected for measurement. A. mRNA and protein changes in PTECs incubated with p44/42 inhibitor; B. mRNA and protein changes in PTECs incubated with p38 inhibitor.

Figure 4. BMP7 suppressed phosphorylation of p38, p44/42 induced by AGEs. PTECs were treated with AGEs $(100 \mu \mathrm{g} / \mathrm{mL})$ or AGEs plus BMP7 $(100 \mathrm{ng} / \mathrm{mL})$ for $30 \mathrm{~min}$; Nil denotes medium control. Bars are means $\pm \mathrm{SD}$ of three independent experiments.

Figure 5. BMP7 attenuated AGEs induced reactive oxygen species (ROS) accumulation in PTECs. PTECs were cultured in chamber slides with A. plain medium, B. H2O2 $500 \mu \mathrm{M}$ as positive control, C. AGEs $100 \mu \mathrm{g} / \mathrm{mL}$ and D. AGEs $100 \mu \mathrm{g} / \mathrm{mL}$ plus BMP7 $100 \mathrm{ng} / \mathrm{mL}$ for $1 \mathrm{~h}$. ROS generation was detected by immunofluorescence signals using a Leica microscope (Magnification: 100X); E. Quantitative data of green fluorescent signals. Results were obtained from three independent experiments, and data was presented as fold change of Integrated Optical Density (IOD) vs medium control, ${ }^{*} p<0.05$; F. Intracellular ROS quantified by OxiSelectTM Intracellular ROS Assay Kit. Data were from three independent experiments, and results presented as ROS concentration, $* * p<0.01$.

Figure 6. BMP7 improved renal morphology in diabetic kidney. Representative periodic acid-Schiff staining of the renal cortical sections in uninephrectomized $d b / m$ mice (A), sham-operated $d b / d b$ mice (B), Unx- $d b / d b$ vehicle-treated mice (C), and Unx- $d b / d b$ BMP7-treated mice (D). Magnification 400X. E. Quantification of glomerular tubulointerstitium damage using ImagePro plus, and expressed as IOD /Area $\mathrm{x} 10^{5} .{ }^{*} p<0.05$, $* * p<0.01$. 
Figure 7. BMP7 attenuated renal cortical inflammation. A. Renal cortical ICAM1 and MCP1 mRNA expression, determined by real-time PCR. B. Renal cortical protein levels of ICAM1 and MCP1, determined by ELISA and normalized by total protein levels of tissue lysates. ${ }^{*} p<0.05, * * p<0.01$.

Figure 8. BMP7 attenuated macrophage infiltration in diabetic mice. Representative renal cortical sections of F4/80 immunostaining in uninephrectomized $d b / m$ mice (A), sham-operated $d b / d b$ mice (B), Unx- $d b / d b$ vehicle-treated mice (C), and Unx- $d b / d b$ BMP7-treated mice (D). Magnification 400X. E. Quantification presented as number of $\mathrm{F} 4 / 80^{+}$cells (red arrows) per high power field. ${ }^{*} p<0.05$.

Figure 9. BMP7 suppressed p38 and p44/42 phosphorylation in diabetic mice. Renal cortical p38 and p44/42 phosphorylation was determined by Western blot and quantified by ChemiDoc software. Samples were randomly picked up in each group ( $d b / d b$ sham: 3/10, Unx- $d b / d b$ BMP7: 5 /10, Unx- $d b / d b$ vehicle: $5 / 11$, respectively). ${ }^{*} p<0.05$.

Figure 10. BMP7 reduced cortical lipid peroxidation in diabetic kidney. Cortical levels of lipid peroxidation were determined using OxiSelect ${ }^{\mathrm{TM}}$ TBARS Assay Kit, and data was presented as fold change of MDA-TBA adduct compared with the $d b / d b$ sham groups. $* * p<0.01$. 
Table 1. Physical and biochemical parameters of experimental animals ( $\mathrm{n}=10-11$ per group)

\begin{tabular}{llllll}
\hline \multirow{2}{*}{ Parameter } & & \multicolumn{2}{c}{$\mathrm{db} / \mathrm{m}$} & \multicolumn{3}{c}{$\mathrm{db} / \mathrm{db}$} \\
\cline { 3 - 6 } & & \multicolumn{1}{c}{$\mathrm{Unx}$} & Sham+vehicle & Unx+BMP7 & Unx+vehicle \\
\hline Body & baseline & $24.45 \pm 0.53^{*}$ & $41.1 \pm 0.92$ & $40.16 \pm 0.85$ & $39.77 \pm 0.45$ \\
weight $(\mathrm{g})$ & 8 weeks & $26.95 \pm 0.43^{*}$ & $49.58 \pm 1.59$ & $50.85 \pm 2.22$ & $46.02 \pm 1.30$ \\
Blood & baseline & $9.86 \pm 0.31^{*}$ & $16.35 \pm 1.33$ & $16.51 \pm 1.27$ & $16.89 \pm 1.66$ \\
glucose (mM) & 8 weeks & $8.24 \pm 0.35^{*}$ & $26.59 \pm 0.90$ & $26.48 \pm 2.36$ & $27.44 \pm 1.70$ \\
Systolic BP & baseline & $117.4 \pm 5.36$ & $116.6 \pm 2.45$ & $124.5 \pm 7.86$ & $123.6 \pm 6.36$ \\
(mmHg) & 8 weeks & $130.7 \pm 5.15^{@}$ & $119.9 \pm 11.29$ & $120.0 \pm 9.79$ & $124.8 \pm 13.10$ \\
UACR & baseline & $437.9 \pm 26.44^{*}$ & $4220 \pm 356.6$ & $4395 \pm 830.7$ & $4068 \pm 397.5$ \\
$(\mu \mathrm{g} / \mathrm{mg})$ & 8 weeks & $404.3 \pm 57.14^{*}$ & $3371 \pm 1029^{\&}$ & $3549 \pm 816.2^{\#}$ & $8612 \pm 2037$ \\
BUN & baseline & $21.02 \pm 0.97^{*}$ & $31.82 \pm 1.99$ & $33.32 \pm 2.17$ & $35.14 \pm 1.35$ \\
$(\mathrm{mg} / \mathrm{dL})$ & 8 weeks & $32.69 \pm 0.89^{@}$ & $28.98 \pm 1.93^{\&}$ & $33.26 \pm 1.09^{\#}$ & $37.49 \pm 0.89$ \\
\hline
\end{tabular}

Unx, uninephrectomy; * $p<0.05 v s d b / d b$ animals, ${ }^{\circledR} p<0.05$ vs baseline, ${ }^{\sharp} p<0.05$ vs Unx- $d b / d b$ vehicle group, ${ }^{\varepsilon_{*}} p<0.05$ vs Unx- $d b / d b$ vehicle group. 
Table 2. Primer sequences for real-time PCR

\begin{tabular}{|c|c|c|c|}
\hline Gene & Species & Accession number & Primer sequence \\
\hline \multirow{2}{*}{ ICAM1 } & & \multirow{2}{*}{ NM_000201.2 } & Forward-5'-GGC CTC AGT CAG TGT GA-3' \\
\hline & & & Reverse-5'-AAC CCC ATT CAG CGT CA-3' \\
\hline \multirow{2}{*}{ IL-8 } & & \multirow{2}{*}{ NM_000584.3 } & Forward-5'-GTG CAG TTT TGC CAA GGA GT-3' \\
\hline & & & Reverse-5'-TAA TTT CTG TGT TGG CGC AG-3' \\
\hline \multirow{2}{*}{ MCP1 } & Homo & \multirow{2}{*}{ NM_002982.3 } & Forward-5'-GAT CTC AGT GCA GAG GCT CG-3' \\
\hline & Sapiens & & Reverse-5'-TGC TTG TCC AGG TGG TCC AT-3' \\
\hline \multirow{2}{*}{ IL-6 } & & \multirow{2}{*}{ NM_000600.3 } & Forward-5'-ATG AAC TCC TTC TCC ACA AG-3' \\
\hline & & & Reverse-5'-TGT CAA TTC GTT CTG AAG AG-3' \\
\hline \multirow{2}{*}{$\beta$-actin } & & \multirow{2}{*}{ NM_001101.3 } & Forward-5'- TGA CGT GGA CAT CCG CAA AG -3' \\
\hline & & & Reverse-5’' CTG GAA GGT GGA CAG CGA GG -3' \\
\hline \multirow{2}{*}{ ICAM1 } & & \multirow{2}{*}{ NM_010493.2 } & Forward-5'-TGG CCT GGG GGA TGC ACA CT -3' \\
\hline & & & Reverse-5'-GGC TGT AGG TGG GTC CGG G -3' \\
\hline \multirow{2}{*}{ MCP1 } & Mus & \multirow{2}{*}{ NM_011333.3 } & Forward-5'-CTC TTC CTC CAC CAC CAT-3' \\
\hline & Musculus & & Reverse-5' - CTC TCC AGC CTA CTC ATT G-3' \\
\hline \multirow{2}{*}{$\beta$-actin } & & \multirow{2}{*}{ NM_007393.3 } & Forward-5'- TCC ATC ATG AAG TGT GAC GT -3' \\
\hline & & & Reverse-5'-GAG CAA TGA TCT TGA TCT TCA T-3' \\
\hline
\end{tabular}

Abbreviations: ICAM1: Intercellular Adhesion Molecule 1; MCP1: monocyte chemoattractant protein-1; IL-8: Interleukin 8; IL-6: Interleukin 6. 

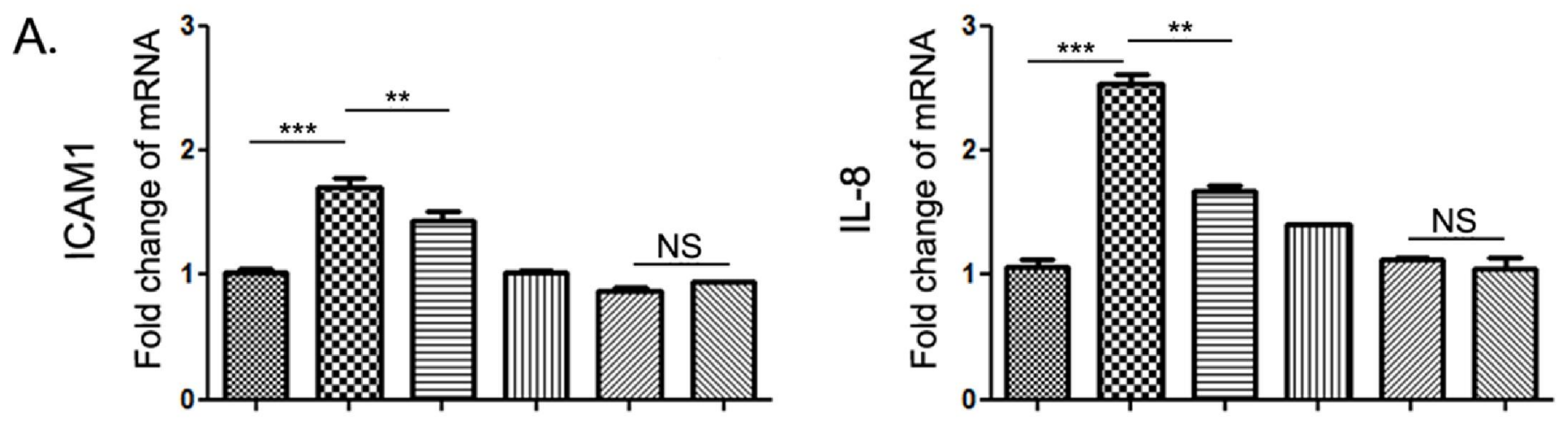

AGEs $100 \mu \mathrm{g} / \mathrm{mL}$ -

AGEs $100 \mu \mathrm{g} / \mathrm{mL}$.
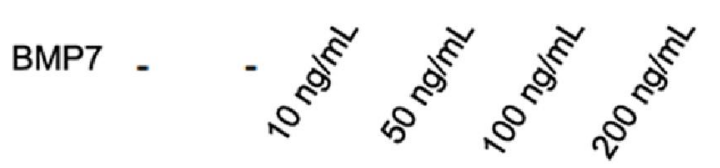

BMP7

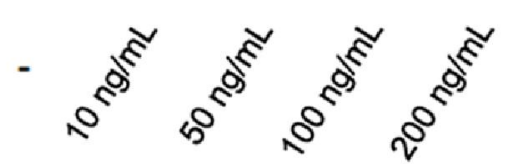

B.
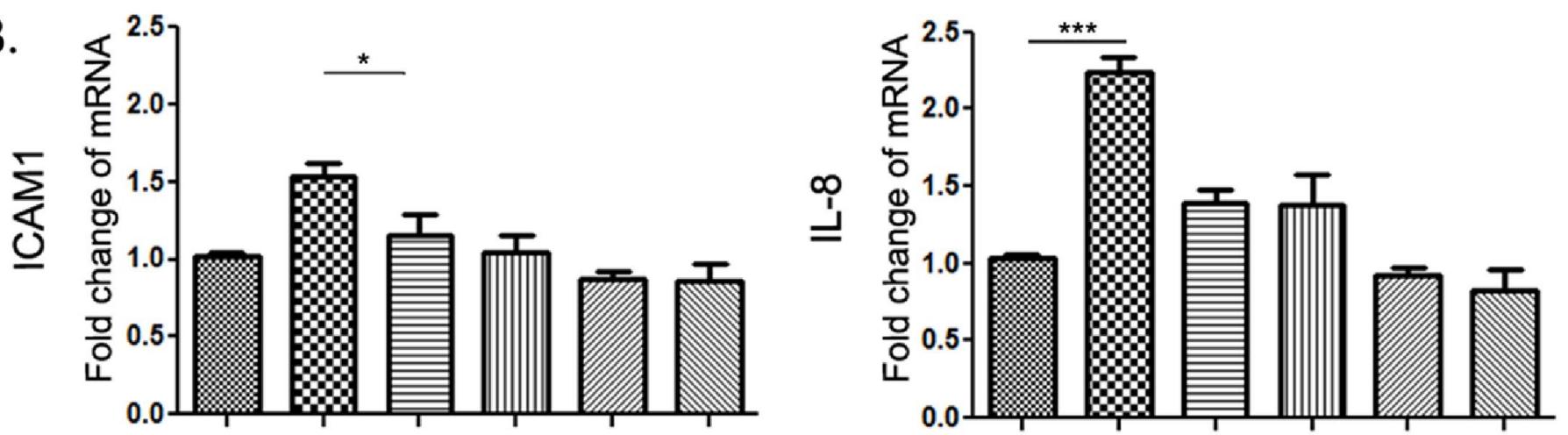

AGEs $100 \mu \mathrm{g} / \mathrm{mL}$ -

HSA $100 \mu \mathrm{g} / \mathrm{mL}$

BMP7 $100 \mathrm{ng} / \mathrm{mL}$

AGEs $100 \mu \mathrm{g} / \mathrm{mL}$ -

HSA $100 \mu \mathrm{g} / \mathrm{mL}$ -

BMP7 $100 \mathrm{ng} / \mathrm{mL}$ - 
Figure 2

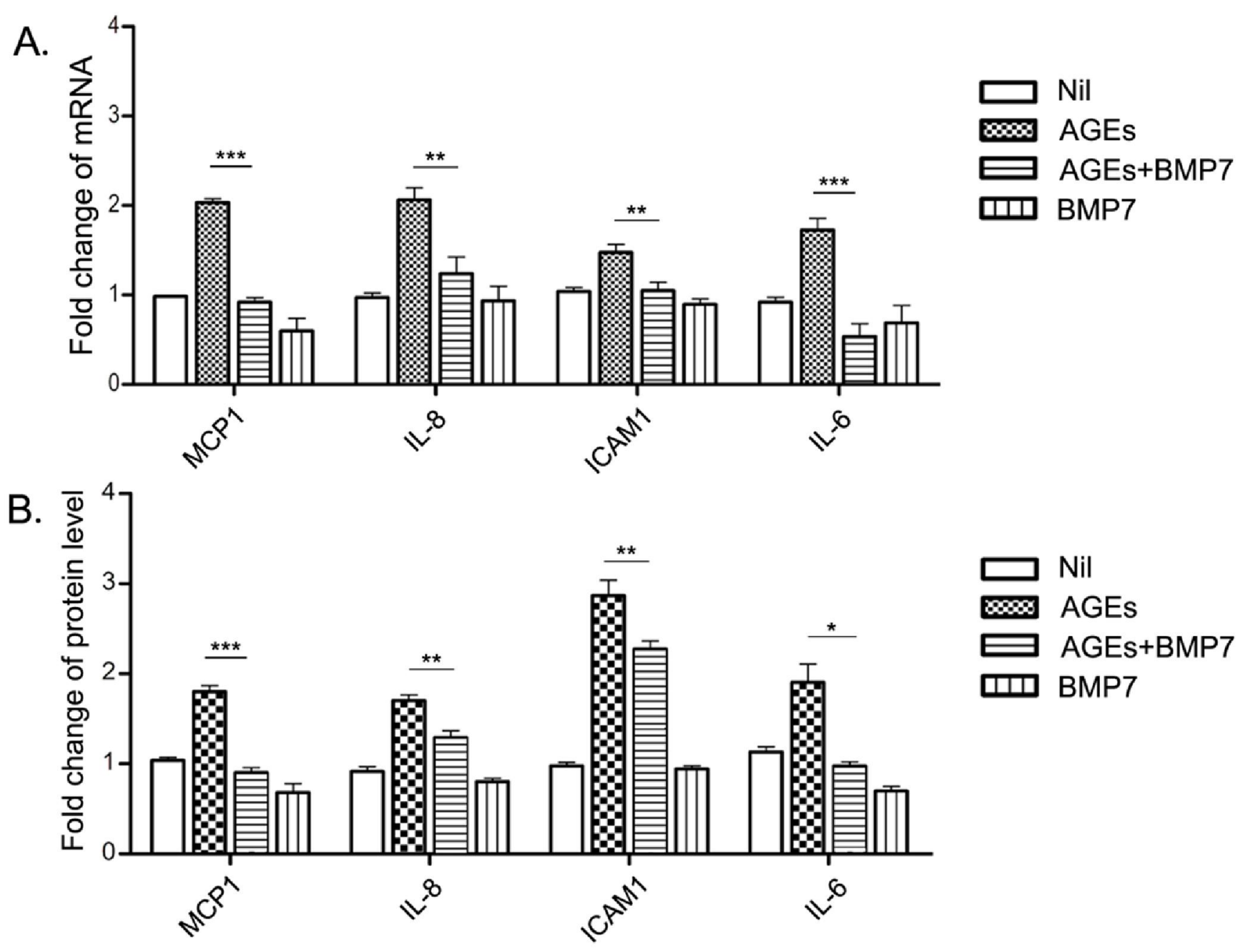




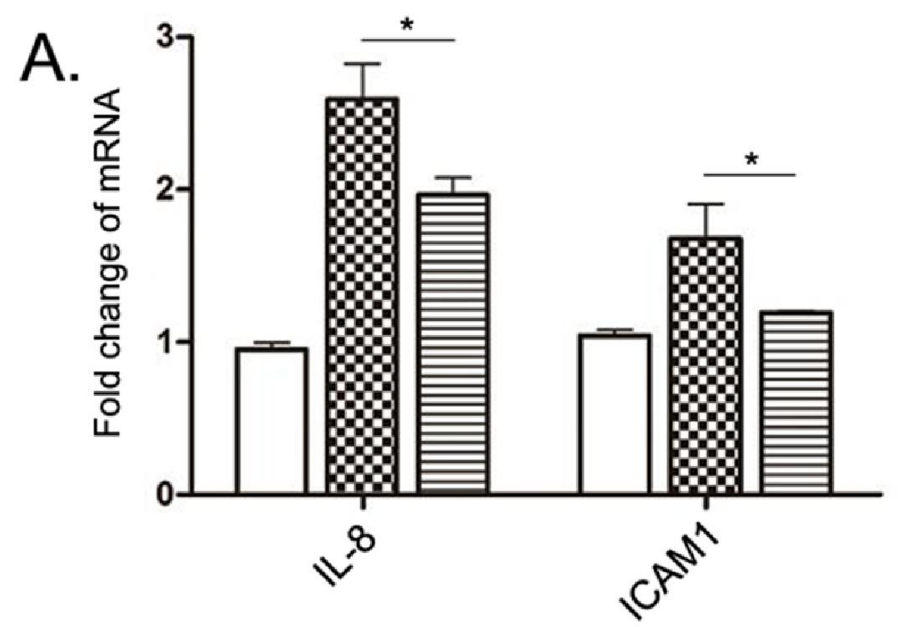

p44/42 inhibitor PD98059

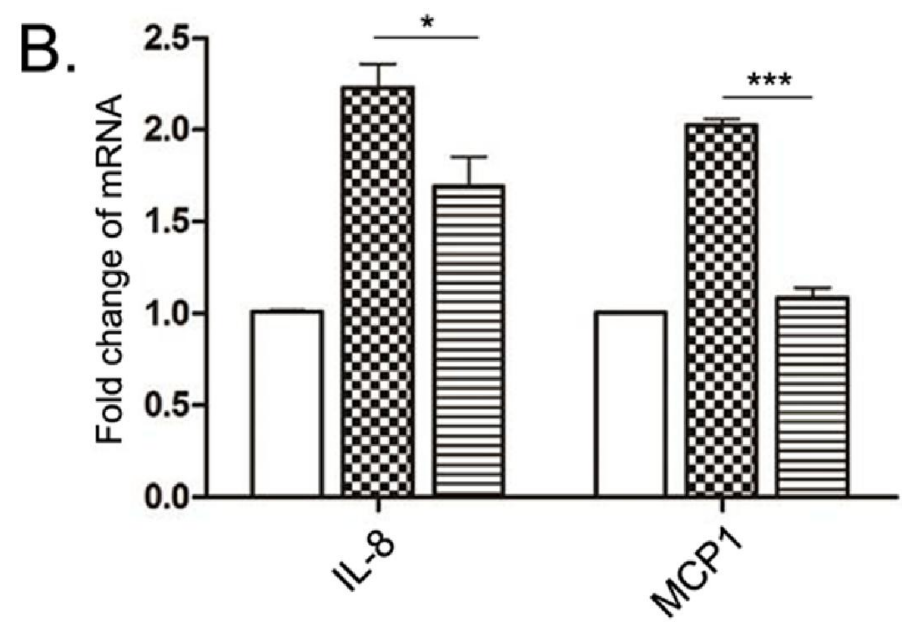

p38 inhibitor SB203580
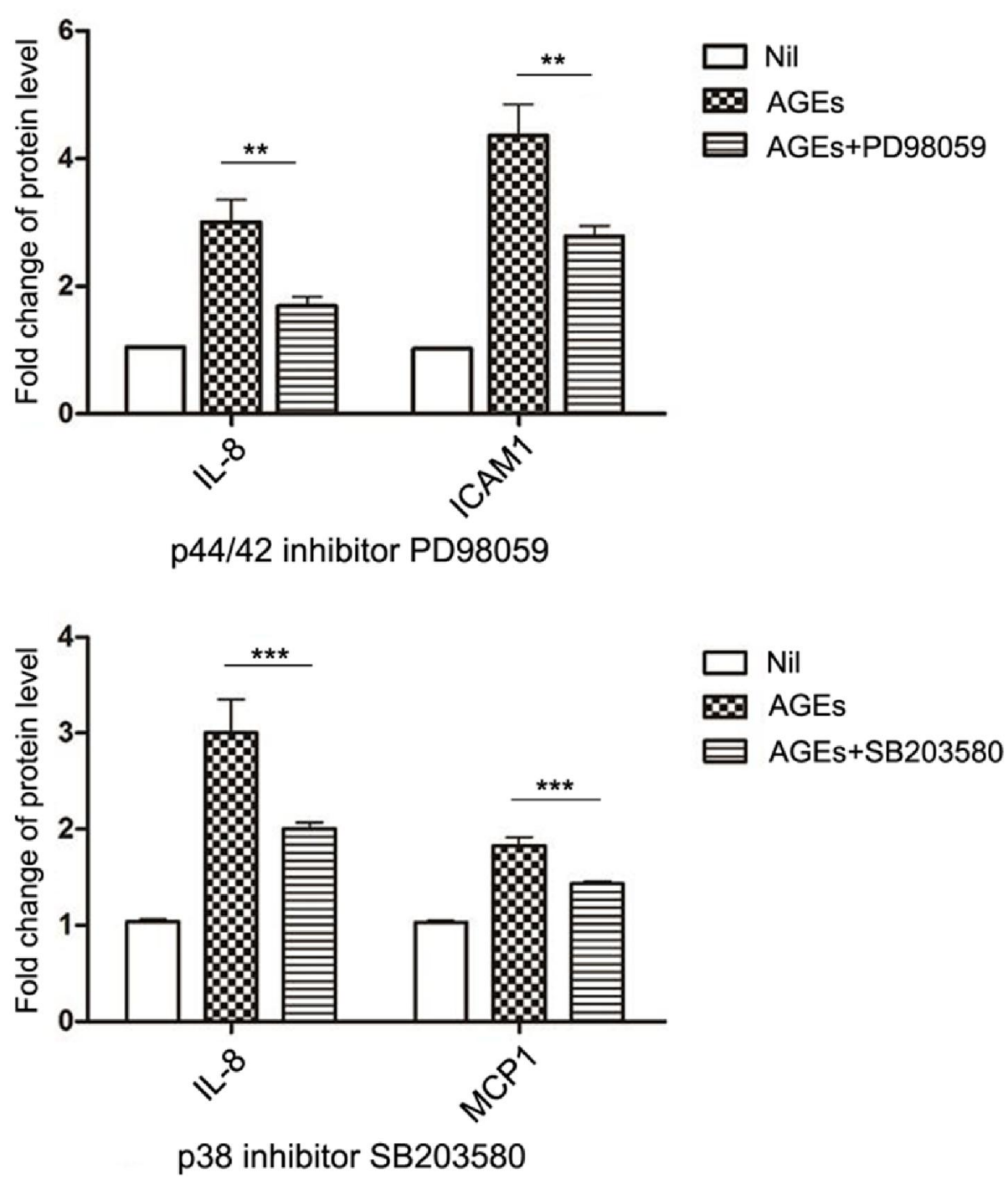
Figure 4

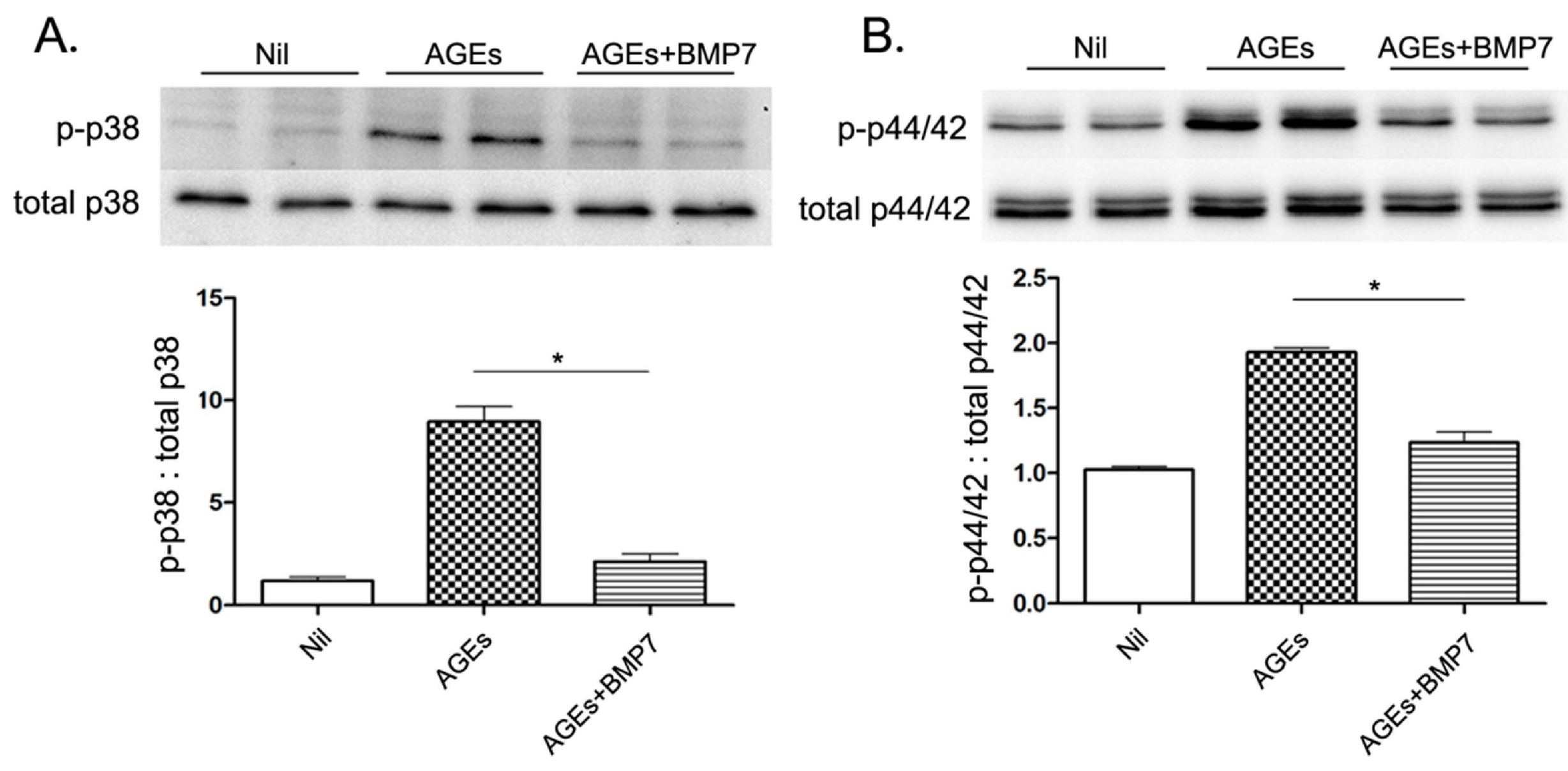


Figure 5
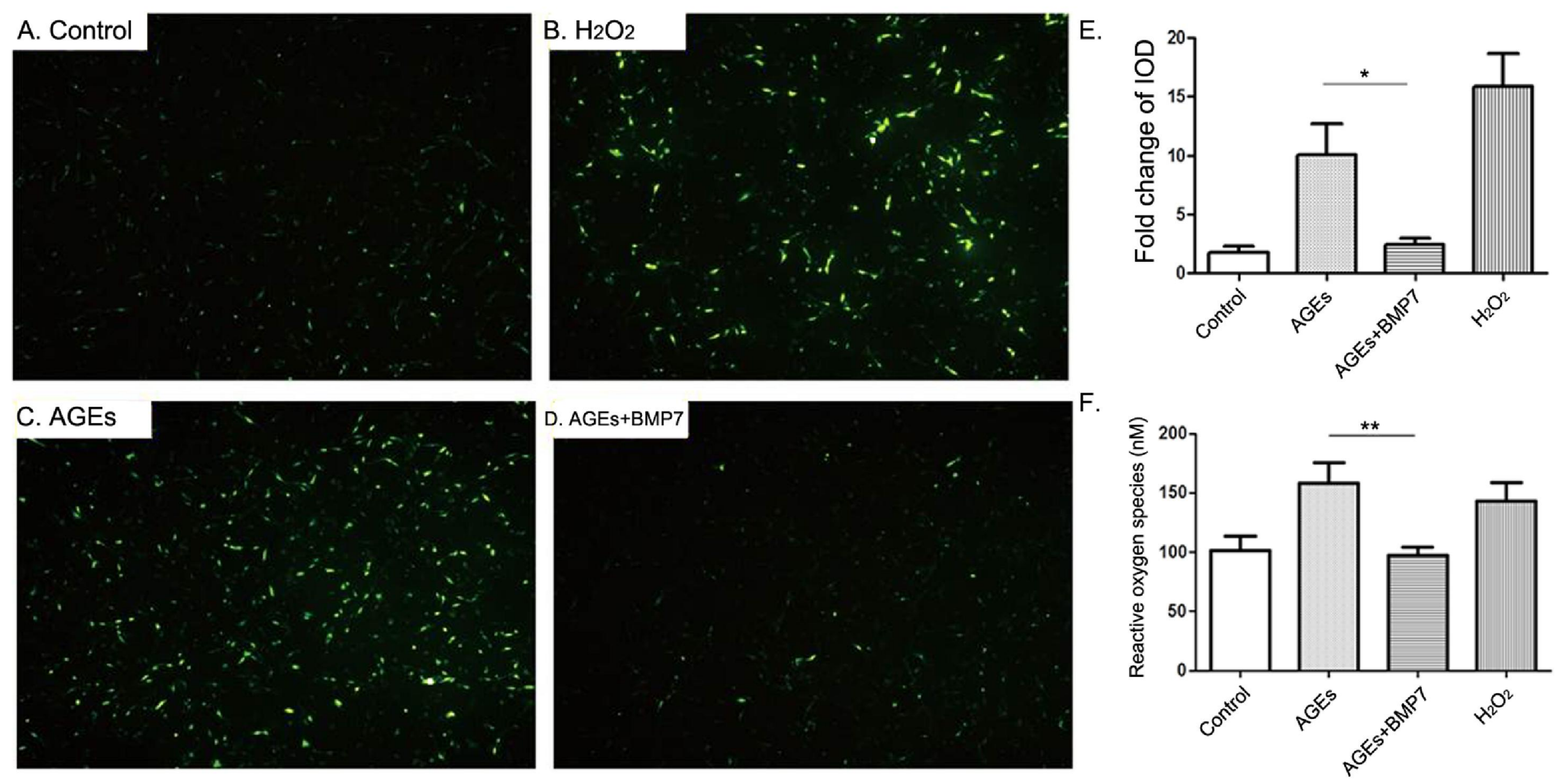
Figure 6

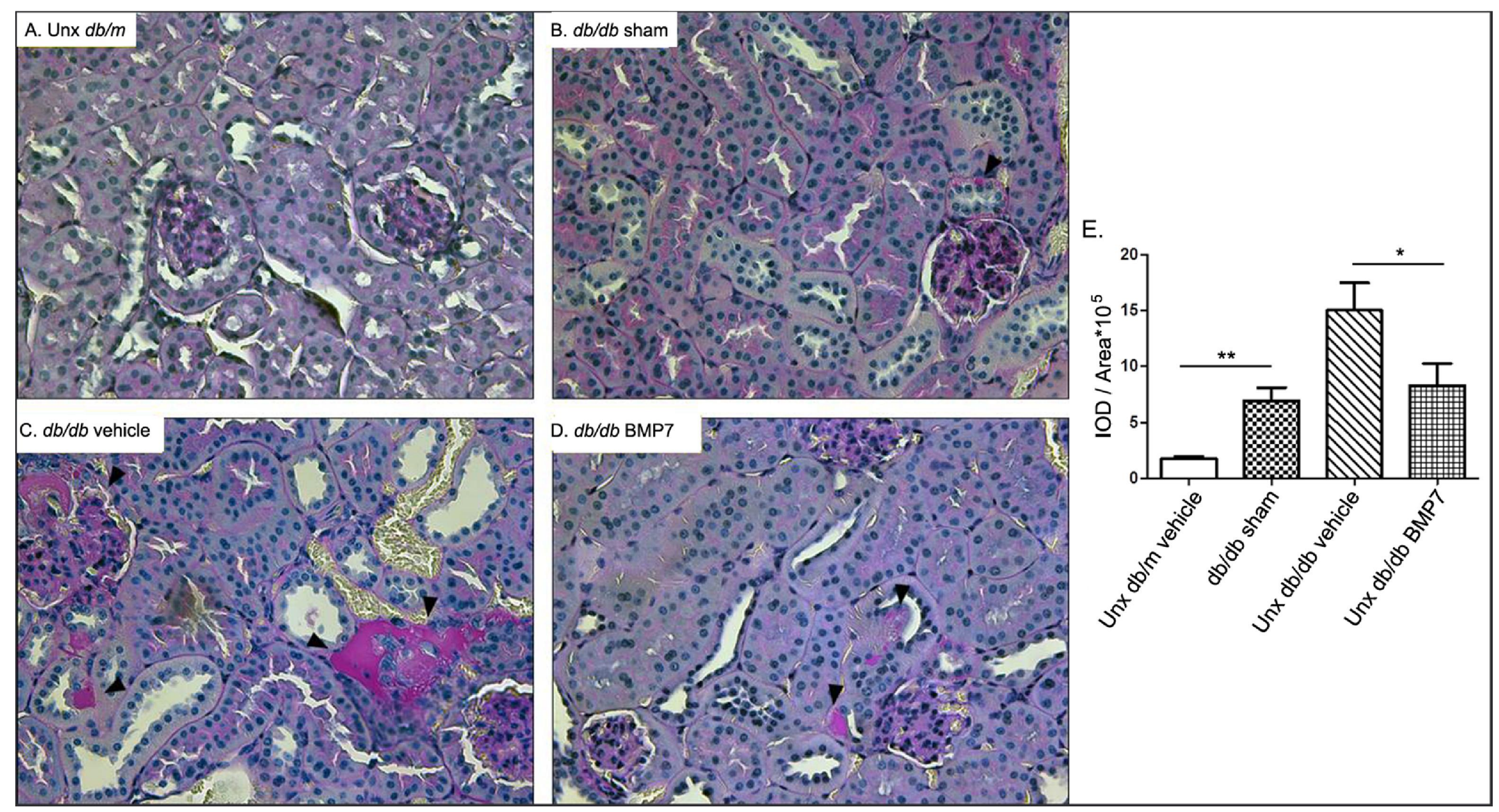


Figure 7
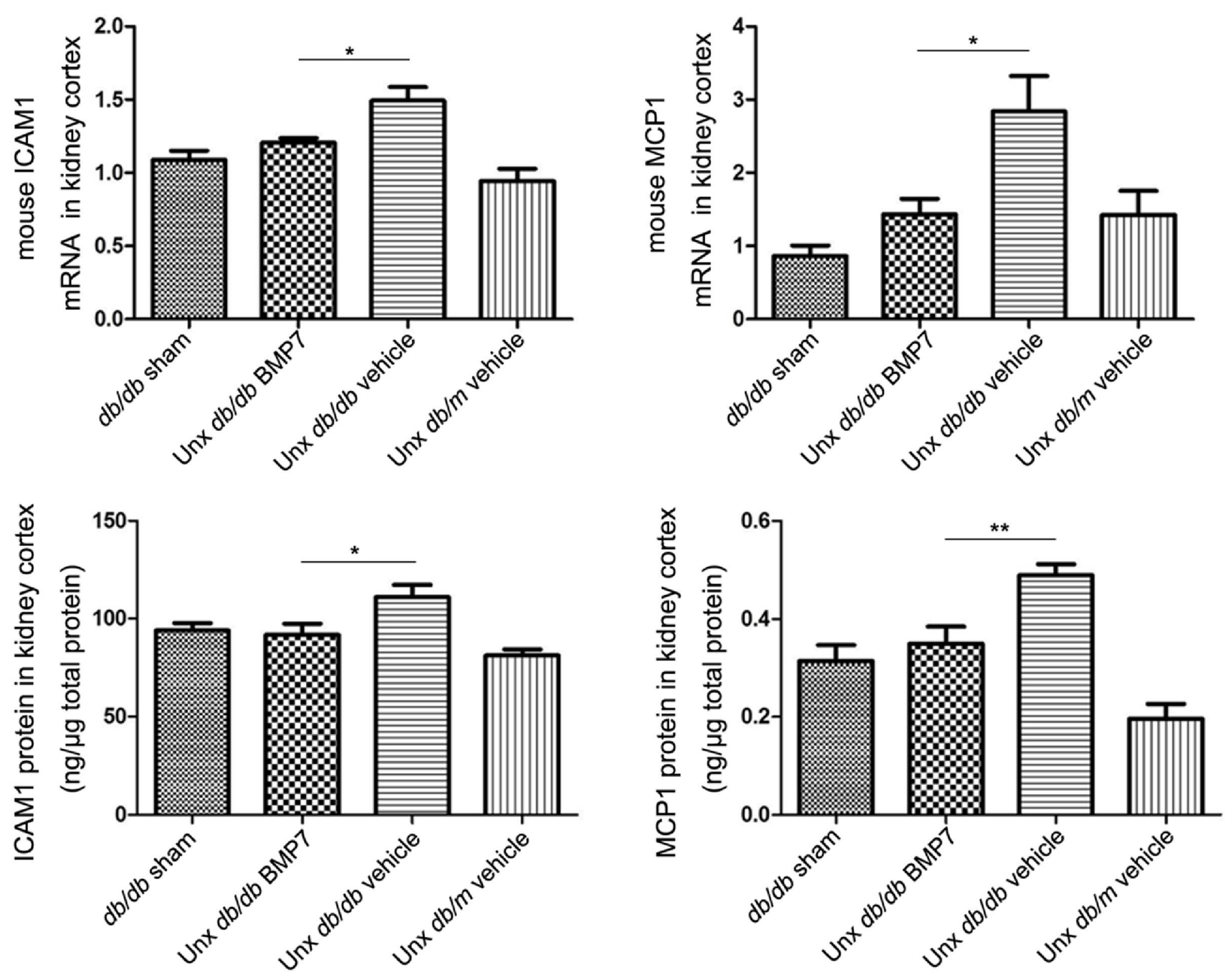
Figure 8

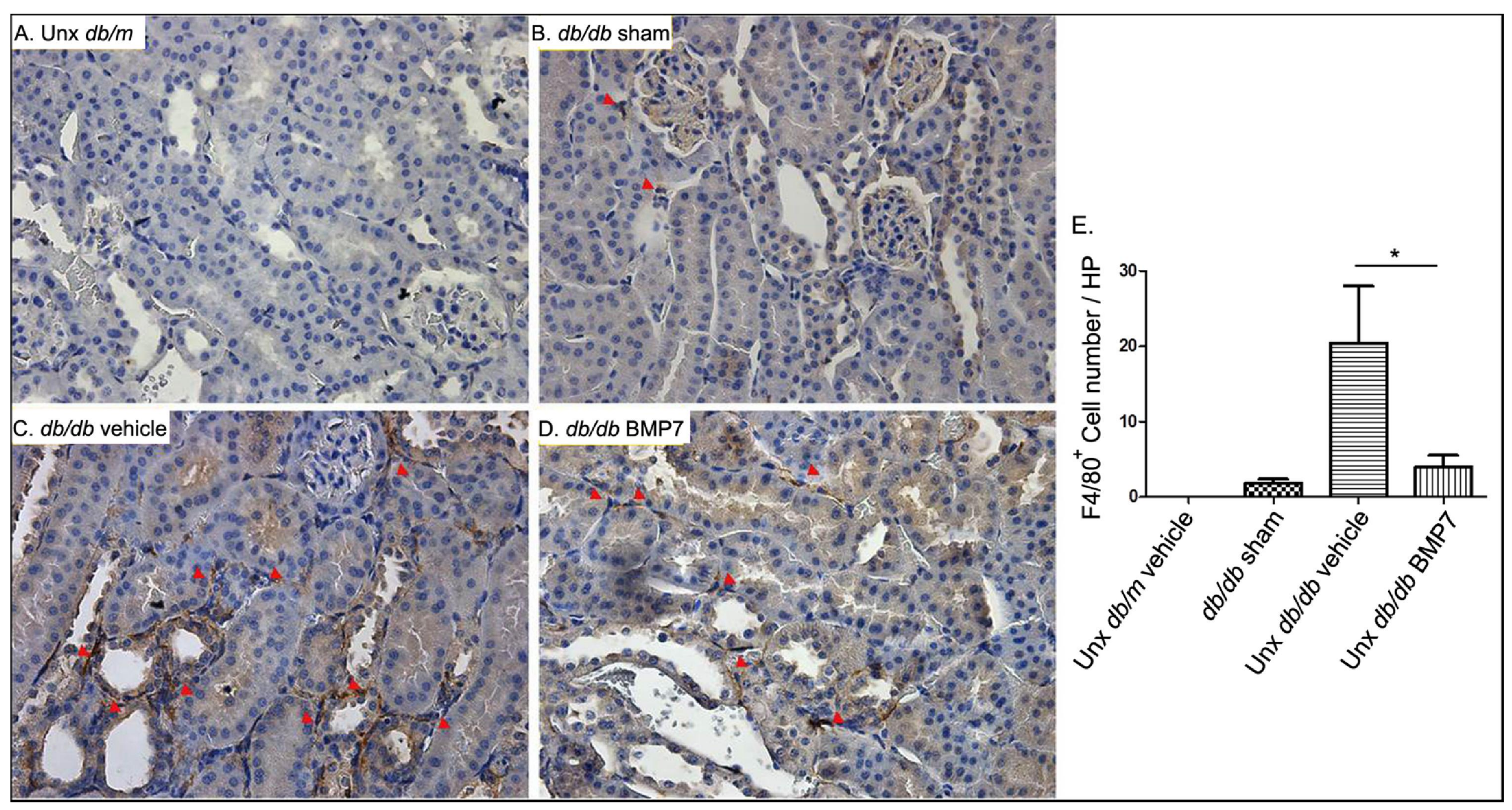



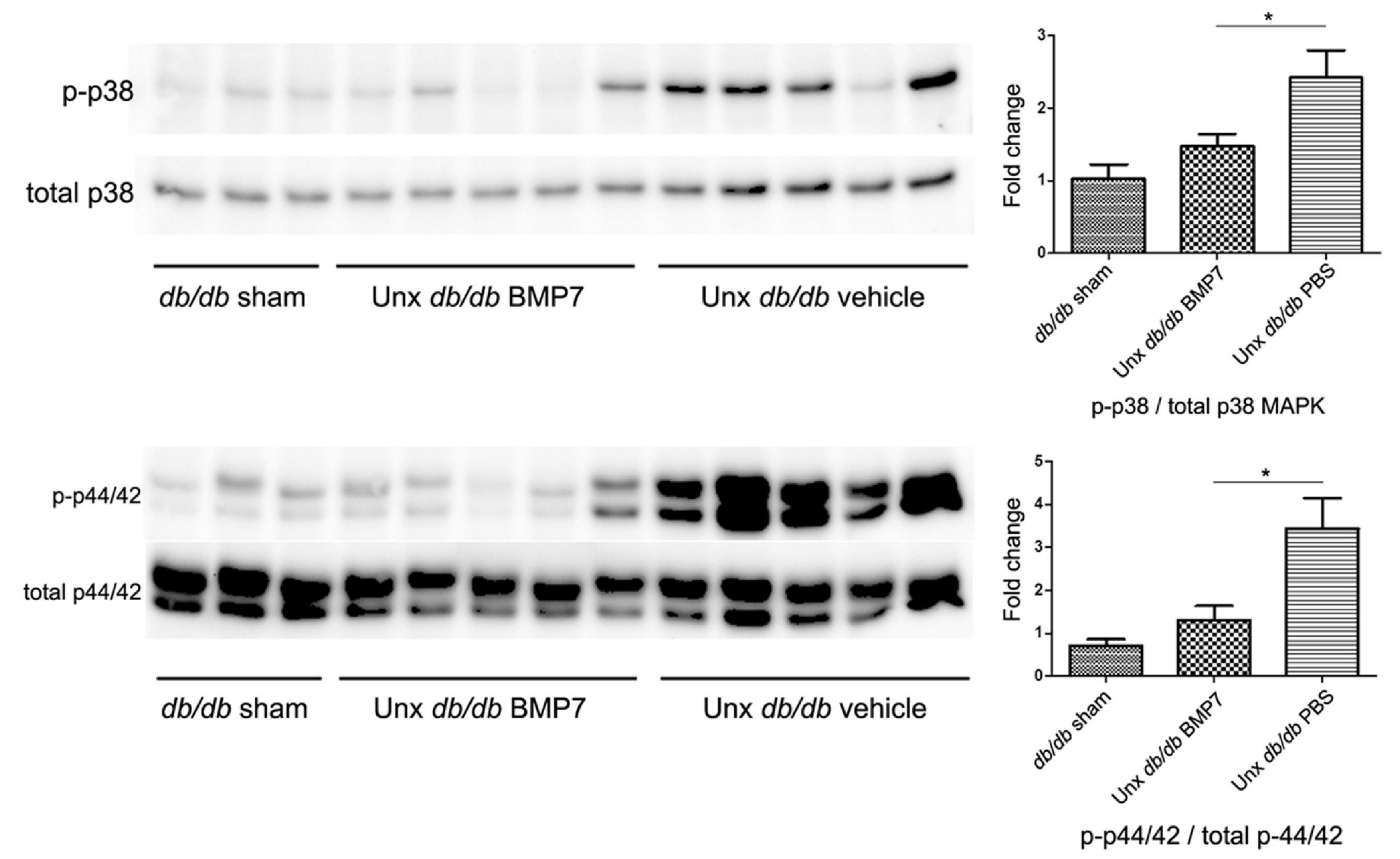
Figure 10

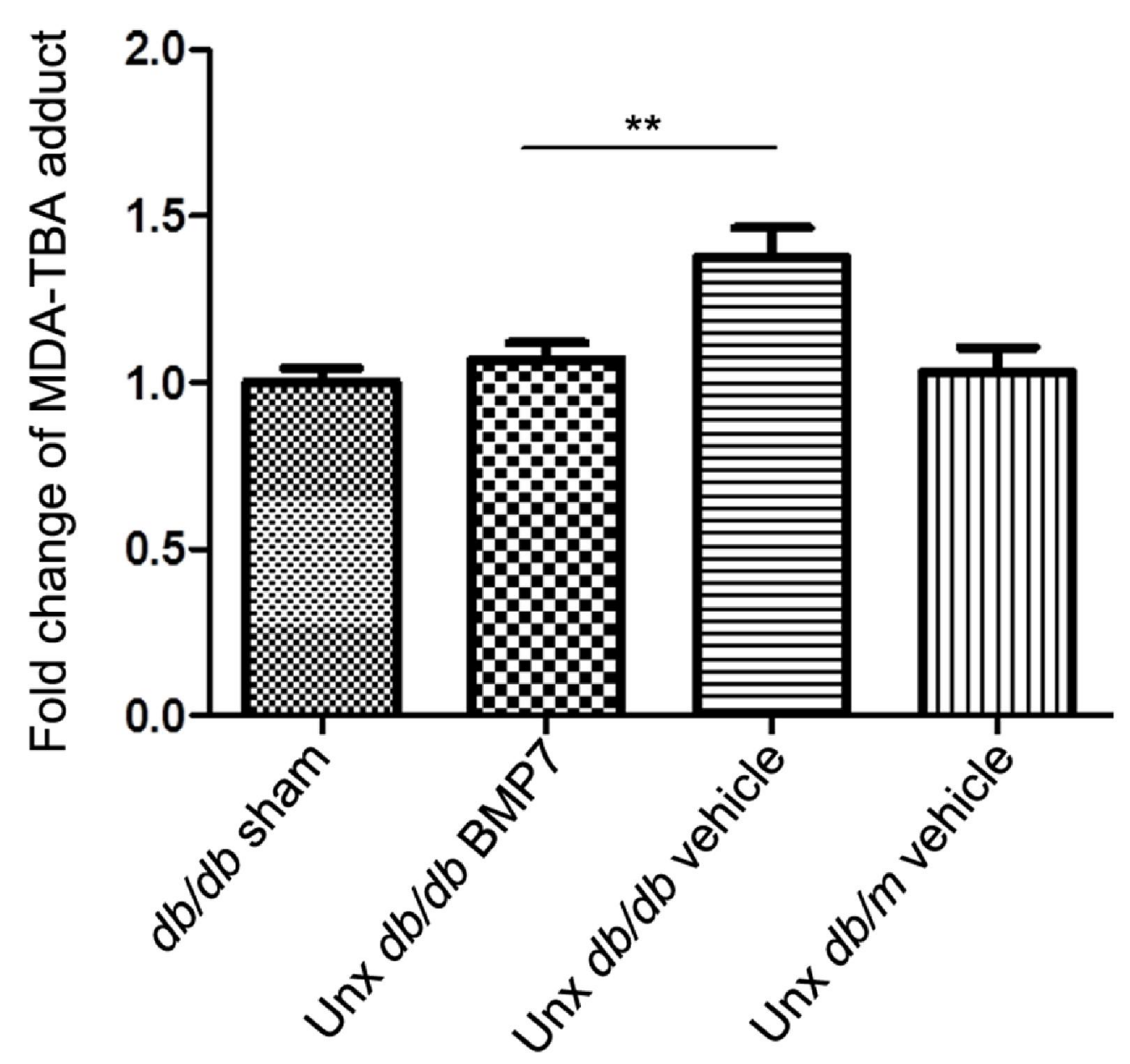

